\title{
Optimal use of anthracycline-free perioperative chemotherapy in HER2-positive breast cancer patients
}

\author{
Rurina Watanuki ${ }^{1}$. Tetsu Hayashida ${ }^{1}$ - Yuko Kawai ${ }^{1}$. Masayuki Kikuchi ${ }^{1}$ - Ayako Nakashoji ${ }^{1}$ Takamichi Yokoe ${ }^{1}$. \\ Tomoka Toyota ${ }^{1} \cdot$ Tomoko Seki $^{1} \cdot$ Maiko Takahashi ${ }^{1} \cdot$ Yuko Kitagawa ${ }^{1}$
}

Received: 15 January 2019 / Accepted: 20 February 2019 / Published online: 27 February 2019

(c) Japan Society of Clinical Oncology 2019

\begin{abstract}
Purpose In adjuvant settings of human epidermal growth factor receptor 2 (HER2)-positive breast cancer, anthracyclinebased chemotherapy followed by taxane and trastuzumab is a standard regimen. Recent studies have reported the use of anthracycline-free adjuvant chemotherapy in selected HER2-positive breast cancer patients. We conducted a single-center retrospective study to identify the characteristics of HER2-positive breast cancer patients for whom anthracyclines can be safely omitted.

Methods A total of 238 women were diagnosed with HER2-positive breast cancer and treated with neoadjuvant and/or adjuvant chemotherapy between January 1, 2008 and December 31, 2015 at Keio University Hospital. They were divided in two cohorts: an "anthracycline" cohort of 112 anthracycline-treated women and a "no anthracycline" cohort of 126 anthracycline-untreated women. Survival outcomes were estimated by Kaplan-Meier method.

Results The 3-year disease-free survival rates in the no-anthracycline and anthracycline cohorts were $91.3 \%$ and $93.1 \%$, respectively $(P=0.692)$. After using a statistical method with inverse probability of treatment weighting to minimize the selection bias, no significant differences were observed between the two cohorts (adjusted hazard ratio for disease-free survival: $1.042 ; P=0.909)$. Stratified by tumor size, no significant differences were observed between the two cohorts in the cT1N0 and cT2N0 subsets ( $P=0.516$ and $P=0.579$, respectively). The recurrence rate was low among patients who achieved pathological complete response after receiving neoadjuvant chemotherapy with or without anthracyclines.

Conclusion Our study suggests that anthracyclines can be safely omitted in selected patients with HER2-positive breast cancer, who have cT1N0 or cT2N0 and achieved pathological complete response after receiving neoadjuvant chemotherapy.
\end{abstract}

Keywords HER2-positive breast cancer · Anthracycline · Adjuvant chemotherapy · Pathological complete response

$\begin{array}{ll}\text { Abbreviations } \\ \text { CI } & \text { Confidence interval } \\ \text { DFS } & \text { Disease-free survival } \\ \text { HER2 } & \text { Human epidermal growth factor receptor 2 } \\ \text { IPTW } & \text { Inverse probability of treatment weighting } \\ \text { NCCN } & \text { National Comprehensive Cancer Network } \\ \text { OS } & \text { Overall survival } \\ \text { pCR } & \text { Pathological complete response }\end{array}$

Tetsu Hayashida tetsu@z7.keio.jp

1 Department of Surgery, Keio University School of Medicine, 35 Shinanomachi, Shinjyuku, Tokyo 160-8582, Japan

\section{Introduction}

Human epidermal growth factor receptor 2 (HER2) is overexpressed and/or amplified in 15-20\% of early breast cancer at time of first diagnosis [1-3]. It was associated with an aggressive clinical course of the disease and poor overall survival before the advent of trastuzumab. The addition of HER2-targeted therapies to chemotherapy dramatically improved the overall survival (OS) and disease-free survival (DFS) [4, 5]. In adjuvant settings of HER2-positive cancer, trastuzumab has been shown to be effective in combination with anthracycline-based chemotherapy followed by taxanebased chemotherapy [6-8].

However, the role of anthracyclines for the treatment of breast cancer remained controversial, due to the increased risk of cardiotoxicity and secondary carcinogenesis [9-12]. Recently, additional anthracycline-free treatment regimens 
have also been reported. In a single-arm multicenter trial of 406 patients treated with paclitaxel plus trastuzumab for $<3 \mathrm{~cm}$, lymph node-negative, HER2-positive breast cancer, Tolaney et al. reported a 98.7\% DFS rate at 3 years of followup [13]. In a similar phase II study of 493 patients with stage I or II HER2-positive breast cancer treated with docetaxel plus cyclophosphamide plus trastuzumab, the 2-year DFS rate was $97.8 \%$ and the 2-year OS rate was $99.5 \%$ [14]. The 2018 National Comprehensive Cancer Network (NCCN) guidelines suggest that paclitaxel plus trastuzumab should be considered in patients with low-risk T1, N0, M0, HER2positive breast cancer [15].

However, there is lack of definitive evidence regarding the use of anthracycline-free regimens in the adjuvant treatment of HER2-positive cancer. Hence, we performed a single-center retrospective cohort study by propensity score-based method using inverse probability of treatment weighting (IPTW) to assess the characteristics of patients in whom anthracyclines can be safely omitted in the adjuvant treatment of HER2-positive breast cancer.

\section{Patients and methods}

\section{Patients}

We performed a single-center retrospective analysis on consecutive patients, who were eventually divided in two cohorts. Patients were diagnosed with pathologically confirmed, HER2-positive breast cancer and treated with neoadjuvant and/or adjuvant chemotherapy between January 1, 2008 and December 31, 2015 at Keio University Hospital. Patients categorized as HER2-positive have an immunohistochemistry score of $3+$ and/or gene amplification ratio of $\geq 2$ by fluorescence in situ hybridization. Women with concurrent bilateral breast cancer, a prior history of invasive breast cancer, or stage IV breast cancer were excluded. The study participants were divided in two cohorts: an "anthracycline" cohort of 112 anthracycline-treated women and a "no anthracycline" cohort of 126 anthracycline-untreated women. In the "anthracycline" cohort, patients were planned to receive 5-fluorouracil at a dose of $500 \mathrm{mg} / \mathrm{m}^{2}$; epirubicin, $100 \mathrm{mg} / \mathrm{m}^{2}$; and cyclophosphamide, $500 \mathrm{mg} / \mathrm{m}^{2}$. In both cohorts, patients were planned to receive paclitaxel at dose of $80 \mathrm{mg} / \mathrm{m}^{2}$ or docetaxel at a dose of $75 \mathrm{mg} / \mathrm{m}^{2}$ with concurrent administration of trastuzumab (a loading dose of $4 \mathrm{mg}$ / $\mathrm{kg}$ on day 1 , followed by $2 \mathrm{mg} / \mathrm{kg}$ weekly in combination with paclitaxel or a loading dose of $8 \mathrm{mg} / \mathrm{kg}$ on day 1 , followed by $6 \mathrm{mg} / \mathrm{kg}$ triweekly in combination with docetaxel).

\section{Outcomes and statistical analysis}

The outcomes of patients who received anthracycline and those who did not receive anthracycline were evaluated. DFS was defined as the period from the date of operation until the date of the first event, including local/regional disease recurrence, distant metastasis, invasive contralateral breast cancer, and death from any cause. The 3-year DFS was estimated with $95 \%$ confidence intervals (CIs) for each cohort using the Kaplan-Meier method. Outcome estimates were compared using the log-rank test. The characteristics of patients who received anthracycline and those who did not receive anthracycline were evaluated using the Fisher's exact test. To minimize treatment selection bias and compare the two cohorts, we fitted a marginal structural model using IPTW [16]. This propensity score-based method mimics the randomized trial design in observational data sets, eliminating bias related to observable confounders $[17,18]$. In the first step, we calculated the probability of treatment with or without anthracycline in a logistic model incorporating confounders associated with treatment and outcome. The score was used to calculate the stabilized inverse probability of treatment weights, which reweighed the population to achieve a similar distribution of variables in both treatment cohorts. The balance was evaluated using standardized mean differences, with a difference of $<0.1$ conventionally indicating adequate bias reduction [19]. Outcomes of the adjusted population were analyzed using marginal structural models, and the adjusted hazard ratio for treatment was evaluated using the Cox hazard model [16].

All $P$ values were two-sided, and $P$ values of 0.05 or less were considered significant. All statistical analyses were performed with R and EZR (Saitma Medical Center, Jichi Medical University), which is a graphical user interface for R (the R Foundation for Statistical Computing, version 3.4.1) [20]. More precisely, it is a modified version of $\mathrm{R}$ commander (version 2.4-1) that was designed to add statistical functions frequently used in biostatistics [20].

\section{Results}

\section{Overall}

Of the 238 eligible patients identified, the baseline characteristics of 126 (53\%) women in the no-anthracycline cohort and those of 112 (47\%) women in the anthracycline cohort are shown in Table 1 . The median age was 
Table 1 Patients' baseline characteristics

\begin{tabular}{|c|c|c|c|}
\hline & $\begin{array}{l}\text { No anthracycline } \\
(n=126) \\
\text { No. }(\%)\end{array}$ & $\begin{array}{l}\text { Anthracycline } \\
(n=112) \\
\text { No. }(\%)\end{array}$ & $P$ value \\
\hline $\begin{array}{l}\text { Median, follow-up } \\
\text { period (month) }\end{array}$ & 46.4 & 61.1 & \\
\hline Median, age (year) & 63 & 55 & $<0.001$ \\
\hline \multicolumn{4}{|l|}{$\mathrm{cT}$} \\
\hline Tis & $18(14)$ & $2(1.8)$ & \multirow[t]{6}{*}{$<0.001$} \\
\hline $\mathrm{T} 1$ & $50(40)$ & $29(26)$ & \\
\hline $\mathrm{T} 2$ & $53(42)$ & $68(61)$ & \\
\hline $\mathrm{T} 3$ & $3(2.4)$ & $11(9.8)$ & \\
\hline $\mathrm{T} 4$ & $1(0.8)$ & $2(1.8)$ & \\
\hline Unknown & $1(0.8)$ & $0(0)$ & \\
\hline \multicolumn{4}{|l|}{$\mathrm{cN}$} \\
\hline No & $112(89)$ & $69(62)$ & \multirow[t]{5}{*}{$<0.001$} \\
\hline N1 & $12(9.5)$ & $38(34)$ & \\
\hline $\mathrm{N} 2$ & $1(0.8)$ & $2(1.8)$ & \\
\hline N3 & $0(0)$ & $3(2.7)$ & \\
\hline Unknown & $1(0.8)$ & $0(0)$ & \\
\hline \multicolumn{4}{|l|}{ Stage } \\
\hline 0 & $18(14)$ & $2(1.8)$ & \multirow[t]{8}{*}{ NA } \\
\hline I & 49 (39) & $25(22)$ & \\
\hline IIA & $45(36)$ & $44(39)$ & \\
\hline IIB & $9(7.1)$ & $29(26)$ & \\
\hline IIIA & $3(2.4)$ & $9(8.0)$ & \\
\hline IIIB & $1(0.8)$ & $0(0)$ & \\
\hline IIIC & $0(0)$ & $3(2.7)$ & \\
\hline Unknown & $1(0.8)$ & $0(0)$ & \\
\hline \multicolumn{4}{|l|}{ ER } \\
\hline Positive & $82(65)$ & $73(65)$ & \multirow[t]{2}{*}{1} \\
\hline Negative & $44(35)$ & $39(35)$ & \\
\hline \multicolumn{4}{|l|}{ PgR } \\
\hline Positive & $65(52)$ & $66(59)$ & \multirow[t]{2}{*}{0.30} \\
\hline Negative & $61(48)$ & $46(41)$ & \\
\hline \multicolumn{4}{|c|}{ Neoadjuvant chemotherapy } \\
\hline Yes & $49(39)$ & $73(65)$ & \multirow[t]{2}{*}{$<0.001$} \\
\hline No & $77(61)$ & $39(35)$ & \\
\hline Recurrence & $9(7.1)$ & $10(8.9)$ & 0.64 \\
\hline
\end{tabular}

$E R$ estrogen receptor, $P g R$ progesterone receptor

63 years (range 35-87 years) and the median follow-up period was 46.4 months in the no-anthracycline cohort. In the anthracycline cohort, the median age was 55 years (range 28-75 years) and the median follow-up period was 61.1 months. The median age of the anthracycline cohort was significantly younger than that of the no-anthracycline cohort $(P<0.01)$. The tumor size of the anthracycline cohort was larger than that of the no-anthracycline cohort $(P<0.01)$. More women in the anthracycline cohort had clinical lymph node metastases $(P<0.01)$. A higher proportion of women in the anthracycline cohort (65\%) received neoadjuvant chemotherapy versus $39 \%$ of the noanthracycline cohort $(P<0.01)$.

The 3-year DFS rates of the no-anthracycline cohort and anthracycline cohorts were $91.3 \%$ (95\% CI 84.0-95.4\%) and 93.1\% (95\% CI 86.1-96.7\%), respectively (Fig. 1a). There were no significant differences between the two cohorts $(P=0.692)$.

\section{Propensity score and inverse probability of treatment weighting analysis}

The characteristics of all patient were not balanced enough to compare the two cohorts. Therefore, IPTW based on propensity score was used to adjust the differences between the two treatment groups. The individual variables used in the propensity model were age, clinical lymph node metastases, stage, and with or without neoadjuvant chemotherapy. The standard mean differences of each variable decreased and were close to 0.1 , which is an index value indicating adequate bias reduction. Although it was difficult to completely remove the selection bias, we could minimize it using this approach (Table 2).

After IPTW adjustment of the propensity score, no significant differences were observed between the two cohorts (adjusted hazard ratio for DFS, 1.042; 95\% CI 0.5111-2.126; $P=0.909$ ).

\section{Subset of cT1 patients}

Next, we stratified the patients according to clinical $\mathrm{T}$ factor to balance the different characteristics of the two cohorts. The baseline characteristics of 50 women in the no-anthracycline cohort and 29 women in the anthracycline cohort in the cT1 subset are shown in Table 3 . The patients' characteristics were almost balanced between the two cohorts except age and clinical lymph node metastases. All women in the no-anthracycline cohort had no clinical lymph node metastases, but four (14\%) patients from the anthracycline cohort experienced lymph node metastases $(P=0.016)$.

The 3-year DFS rates of the no-anthracycline cohort and anthracycline cohort in the cT1 subset were $92.3 \%$ (95\% CI 77.5-97.5\%) and 100\% (95\% CI 100-100\%), respectively (Fig. 1b). There were no significant differences between the two cohorts $(P=0.516)$. Similar results were shown for the cT1N0 subset (Fig. 1c). 
(a)

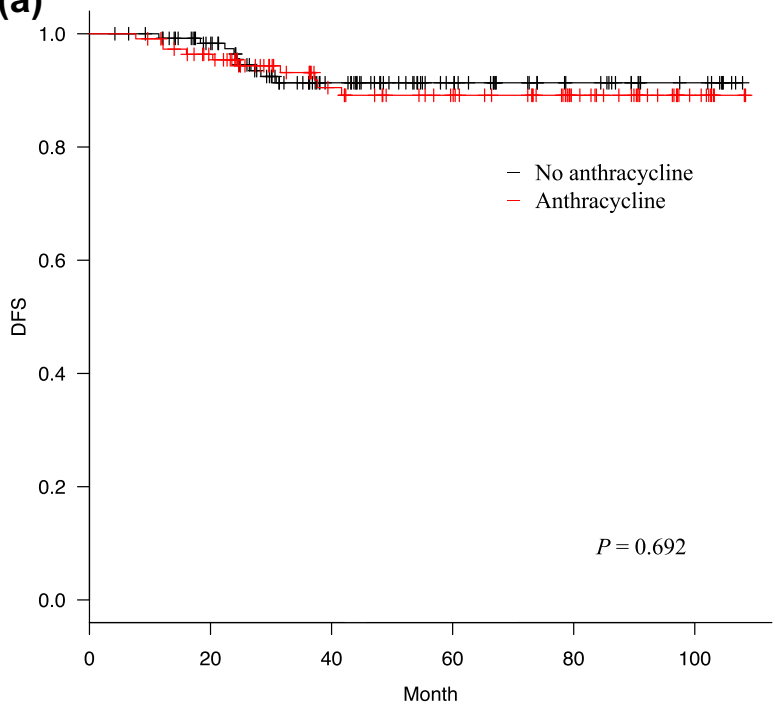

(c)

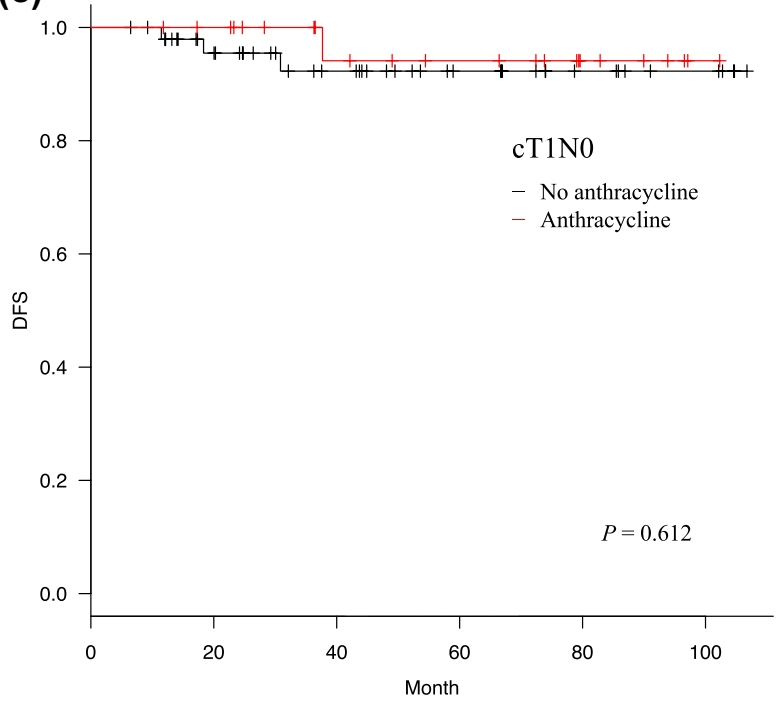

(b)

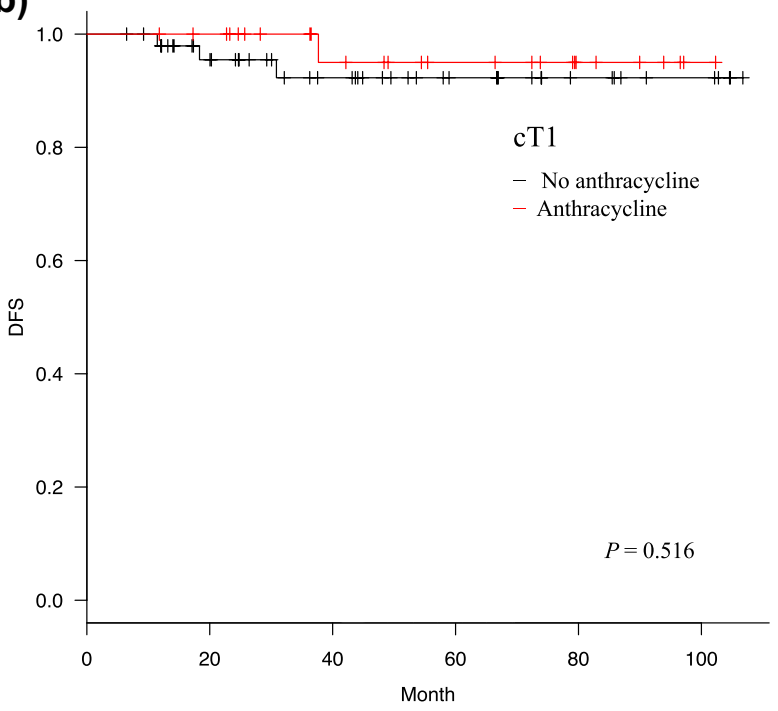

(d)

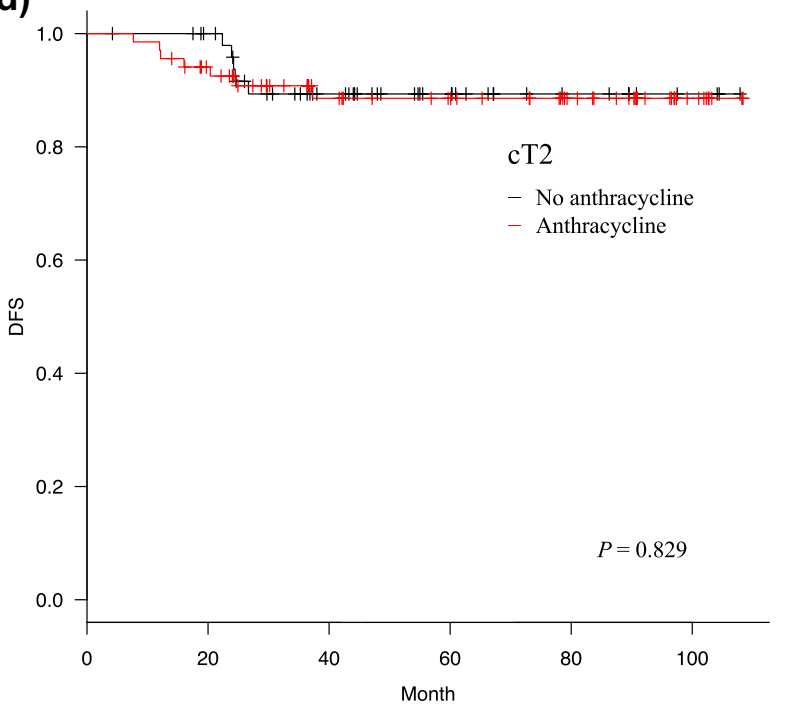

(e)

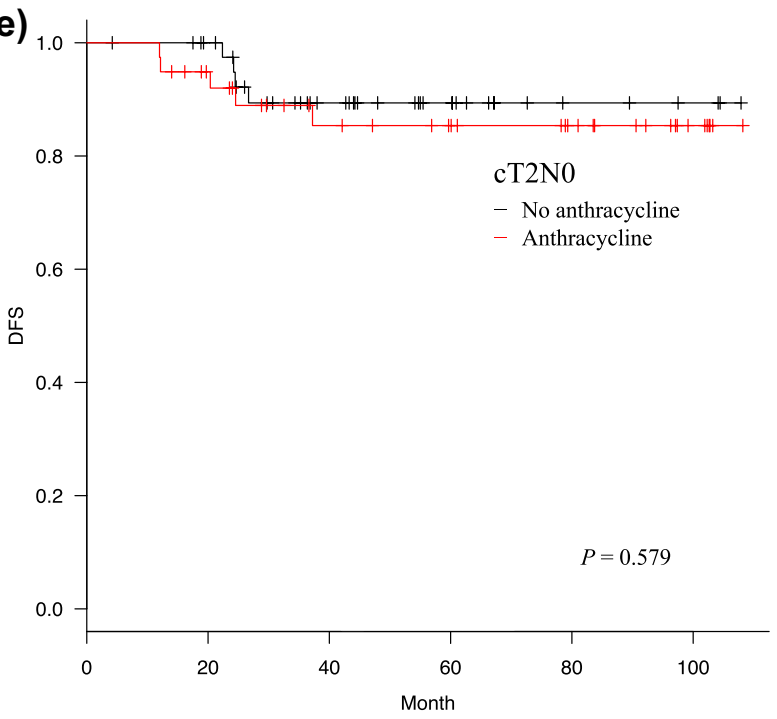


4Fig. 1 Kaplan-Meier curve for disease-free survival. a Disease-free survival for all patients with or without anthracycline, b for cT1 patients with or without anthracycline, $\mathbf{c}$ for cT1N0 patients with or without anthracycline, $\mathbf{d}$ for cT2 patients with or without anthracycline, and e for cT2N0 patients with or without anthracycline

\section{Subset of cT2 patients}

The baseline characteristics of 53 women in the no-anthracycline cohort and 68 women in the anthracycline cohort in the cT2 subset are shown in Table 4. The 3-year DFS rates of the no-anthracycline cohort and anthracycline cohort in the cT2 subset were $89.3 \%$ (95\% CI 76.2-95.4\%) and 90.8\% (95\% CI 80.6-95.8\%), respectively (Fig. 1d). There were no significant differences between the two cohorts in the cT2 subset $(P=0.829)$. However, there were significant differences in age, clinical lymph node metastases, and stage between the two groups. Therefore, we stratified the patients with cT2N0. Results showed that the baseline characteristics of the two cohorts were generally balanced except age (Table 5). The 3 -year DFS rate of cT2N0 patients was illustrated using Kaplan-Meier curves: $89.4 \%$ (95\% CI 74.7-97.0\%) for the no-anthracycline cohort versus $88.9 \%$ (95\% CI 62.0-93.6\%) for the anthracycline cohort (Fig. 1e). No significant differences were found between the two cohorts in the cT2N0 subset $(P=0.579)$.

\section{Patients who received neoadjuvant chemotherapy}

Of the 238 patients, 122 received neoadjuvant chemotherapy and $36(29.5 \%)$ achieved pathological complete response (pCR) (Fig. 2). Of them, 26 patients from the no-anthracycline cohort achieved pCR $(n=49)$, while 10 from the anthracycline cohort achieved pCR $(n=73)$. Among the pCR group, only one patient in each cohort had recurrence.

Table 2 Baseline characteristics of patients weighted by inverse probability of propensity score

\begin{tabular}{|c|c|c|c|c|c|c|}
\hline & \multicolumn{3}{|l|}{ Before IPTW } & \multicolumn{3}{|l|}{ After IPTW } \\
\hline & \multirow{2}{*}{$\begin{array}{l}\text { No anthracycline } \\
(n=126) \\
\text { No. }(\%)\end{array}$} & \multirow{2}{*}{$\begin{array}{l}\text { Anthracycline } \\
(n=112) \\
\text { No. }(\%)\end{array}$} & \multirow[t]{2}{*}{$\begin{array}{l}\text { Standardized mean } \\
\text { difference }\end{array}$} & \multirow{2}{*}{$\begin{array}{l}\text { No anthracycline } \\
(n=237) \\
\text { No. }(\%)\end{array}$} & \multirow{2}{*}{$\begin{array}{l}\text { Anthracycline } \\
(n=239) \\
\text { No. }(\%)\end{array}$} & \multirow[t]{2}{*}{$\begin{array}{l}\text { Standardized } \\
\text { mean differ- } \\
\text { ence }\end{array}$} \\
\hline & & & & & & \\
\hline Age [mean (SD)] & $61.6(11.73)$ & $53.8(9.82)$ & 0.729 & $56.9(13.35)$ & $57.5(9.81)$ & 0.05 \\
\hline $\mathrm{cT}$ & & & 0.707 & & & 0.171 \\
\hline Tis & $18(14)$ & $2(1.8)$ & & $20(8.5)$ & $28(12)$ & \\
\hline $\mathrm{T} 1$ & $50(40)$ & $29(26)$ & & 77 (33) & $78(33)$ & \\
\hline $\mathrm{T} 2$ & $53(42)$ & $68(61)$ & & $124(52)$ & $117(49)$ & \\
\hline $\mathrm{T} 3$ & $3(2.4)$ & $11(9.8)$ & & $13(5.6)$ & $14(5.8)$ & \\
\hline $\mathrm{T} 4$ & $1(0.8)$ & $2(1.8)$ & & $1(0.4)$ & $1(0.4)$ & \\
\hline Unknown & $1(0.8)$ & $0(0)$ & & $1(0.4)$ & 0 & \\
\hline $\mathrm{cN}$ & & & 0.712 & & & 0.228 \\
\hline No & $112(89)$ & $69(62)$ & & $181(76)$ & $185(77)$ & \\
\hline N1 & $12(9.5)$ & $38(34)$ & & 46 (19) & $48(20)$ & \\
\hline $\mathrm{N} 2$ & $1(0.8)$ & $2(1.8)$ & & $9(3.7)$ & $4(1.5)$ & \\
\hline N3 & $0(0)$ & $3(2.7)$ & & $0(0)$ & $3(1.3)$ & \\
\hline Unknown & $1(0.8)$ & $0(0)$ & & $1(0.4)$ & $0(0)$ & \\
\hline Stage & & & 0.879 & & & 0.238 \\
\hline 0 & $18(14)$ & $2(1.8)$ & & $20(8.5)$ & $28(12)$ & \\
\hline I & 49 (39) & $25(22)$ & & $75(32)$ & $73(31)$ & \\
\hline IIA & $45(36)$ & $44(39)$ & & $84(36)$ & $85(36)$ & \\
\hline IIB & $9(7.1)$ & $29(26)$ & & $42(18)$ & 37 (16) & \\
\hline IIIA & $3(2.4)$ & $9(8.0)$ & & $13(5.6)$ & $12(5.0)$ & \\
\hline IIIB & $1(0.8)$ & $0(0)$ & & $1(0.4)$ & $0(0)$ & \\
\hline IIIC & $0(0)$ & $3(2.7)$ & & $0(0)$ & $3(1.3)$ & \\
\hline Unknown & $1(0.8)$ & $0(0)$ & & $1(0.4)$ & $0(0)$ & \\
\hline Neoadjuvant chemotherapy & $49(39)$ & $73(65)$ & 0.545 & $121(51)$ & $121(51)$ & 0.011 \\
\hline
\end{tabular}

$I P T W$ inverse probability of treatment weighting 


\section{Discussion}

The APT trial showed good survival outcomes in patients treated with paclitaxel plus trastuzumab for $<3 \mathrm{~cm}$, lymph node-negative, HER2-positive breast cancer (3-year DFS: 98.7\%) [13]. Another prospective study reported similar survival data in patients who used anthracycline-free regimen with stage I or II HER2-positive breast cancer (2-year DFS: 97.8\%, 2-year OS: 98.2\%) [14]. The point that differed from those reported in previous studies was that our study included more patients with advanced cancer and patients who received neoadjuvant chemotherapy. Both previous studies were prospective in nature but were conducted as single-arm trials. Selection bias can be resolved by conducting a prospective, randomized study. However, to the best of our knowledge, no such clinical trial is ongoing or planned in the near future. Instead, we performed this retrospective, single-center study and made a comparison of the two groups: anthracycline cohort and no-anthracycline cohort.

In this study, the patient characteristics that were biased in the two groups were age, clinical lymph node metastasis, and stage. Anthracyclines tended to be used in young patients who can tolerate chemotherapy and in patients who develop advanced cancer with lymph node metastasis.

Table 3 Baseline characteristics of cT1 patients

\begin{tabular}{|c|c|c|c|}
\hline & $\begin{array}{l}\text { No anthracycline } \\
(n=50)\end{array}$ & $\begin{array}{l}\text { Anthracycline } \\
(n=29)\end{array}$ & $P$ value \\
\hline & No. $(\%)$ & No. (\%) & \\
\hline $\begin{array}{l}\text { Median, follow-up } \\
\text { period (month) }\end{array}$ & 44.5 & 56.3 & 0.18 \\
\hline Median, age (year) & 63.0 & 56 & 0.020 \\
\hline \multicolumn{4}{|l|}{$\mathrm{cN}$} \\
\hline No & $50(100)$ & $25(86)$ & \multirow[t]{4}{*}{0.016} \\
\hline N1 & 0 & $4(14)$ & \\
\hline $\mathrm{N} 2$ & 0 & 0 & \\
\hline N3 & 0 & 0 & \\
\hline \multicolumn{4}{|l|}{ Stage } \\
\hline I & $49(98)$ & $25(86)$ & \multirow[t]{2}{*}{0.058} \\
\hline IIA & $1(2)$ & $4(14)$ & \\
\hline \multicolumn{4}{|l|}{ ER } \\
\hline Positive & $34(68)$ & $22(76)$ & \multirow[t]{2}{*}{0.61} \\
\hline Negative & $16(32)$ & $7(24)$ & \\
\hline \multicolumn{4}{|l|}{ PgR } \\
\hline Positive & $29(58)$ & $21(72)$ & \multirow[t]{2}{*}{0.23} \\
\hline Negative & $21(42)$ & $8(28)$ & \\
\hline \multicolumn{4}{|c|}{ Neoadjuvant chemotherapy } \\
\hline Yes & $13(26)$ & $13(45)$ & \multirow[t]{2}{*}{0.14} \\
\hline No & $37(74)$ & $16(55)$ & \\
\hline Recurrence & $3(6.0)$ & $1(3.4)$ & 1 \\
\hline
\end{tabular}

$E R$ estrogen receptor, $P g R$ progesterone receptor
The elderly, their family and also physicians prefer to avoid highly toxic chemotherapy. These were the reasons why younger and/or more advanced patients were included in the anthracycline cohort. Problems with treatment selection bias were alleviated in both cohorts, but it was not easy to completely eliminate such bias even if a statistical approach with IPTW was utilized. Therefore, we divided the patients into several subsets stratified by tumor size and succeeded in making balanced subsets like cT1N0 and cT2N0. This retrospective study showed that there were no significant differences in the DFS of cT1N0 and cT2N0 patients who received treatment with or without anthracycline between the two groups. Hence, we suggest that we can safely omit anthracyclines in the treatment of cT1N0 and cT2N0 HER2positive breast cancer. In addition, regardless of anthracycline use, the recurrence rate among patients who achieved pCR after neoadjuvant chemotherapy remained low. This result indicated that anthracycline-free regimen is recommended for patients who achieved pCR after receiving neoadjuvant chemotherapy, which is a combination of trastuzumab and taxane.

Table 4 Baseline characteristics of cT2 patients

\begin{tabular}{|c|c|c|c|}
\hline & $\begin{array}{l}\text { No anthracycline } \\
(n=53)\end{array}$ & $\begin{array}{l}\text { Anthracycline } \\
(n=68)\end{array}$ & $P$ value \\
\hline & No. $(\%)$ & No. $(\%)$ & \\
\hline $\begin{array}{l}\text { Median, follow-up } \\
\text { period (month) }\end{array}$ & 54.6 & 64.1 & 0.31 \\
\hline Median, age (year) & 62.7 & 53.1 & $<0.001$ \\
\hline \multicolumn{4}{|l|}{$\mathrm{cN}$} \\
\hline No & $44(83)$ & $39(57)$ & \multirow[t]{4}{*}{0.0048} \\
\hline N1 & $9(17)$ & $27(40)$ & \\
\hline $\mathrm{N} 2$ & $0(0)$ & $1(1.5)$ & \\
\hline N3 & $0(0)$ & $1(1.5)$ & \\
\hline \multicolumn{4}{|l|}{ Stage } \\
\hline IIA & $44(83)$ & $39(57)$ & \multirow[t]{4}{*}{0.0048} \\
\hline IIB & $9(17)$ & $27(40)$ & \\
\hline IIIA & $0(0)$ & $1(1.5)$ & \\
\hline IIIC & $0(0)$ & $1(1.5)$ & \\
\hline \multicolumn{4}{|l|}{ ER } \\
\hline Positive & $34(64)$ & $41(60)$ & \multirow[t]{2}{*}{0.71} \\
\hline Negative & $19(36)$ & $27(40)$ & \\
\hline \multicolumn{4}{|l|}{ PgR } \\
\hline Positive & $29(55)$ & $36(53)$ & \multirow[t]{2}{*}{0.86} \\
\hline Negative & $24(45)$ & $32(47)$ & \\
\hline \multicolumn{4}{|c|}{ Neoadjuvant chemotherapy } \\
\hline Yes & $33(62)$ & $49(72)$ & \multirow[t]{2}{*}{0.33} \\
\hline No & $20(38)$ & $19(28)$ & \\
\hline Recurrence & $5(9.4)$ & $7(10.3)$ & 1 \\
\hline
\end{tabular}

$H R$ hormone receptor, $E R$ estrogen receptor, $P g R$ progesterone receptor 
This study had several limitations. First, the patients' characteristics between the two cohorts were not well balanced, which is a weak point of retrospective studies. Second, the Kaplan-Meier curve showed that the survival rate of the anthracycline cohort is slightly higher than the no-anthracycline cohort in the T1 subset. Although there were no statistically significant differences between the two cohorts in this study, a well designed randomized control trial with enough sample size might be able to prove the significance of anthracycline cohort. Third, we could not identify the possibility of omission of anthracycline in patients with lymph node metastases. Hence, we need a larger sample to assess this problem. In addition, it is important to show that omission of anthracycline can reduce adverse events and improve patients' quality of life. The last limitation is that we did not have satisfying retrospective data on adverse events which we could evaluate systemically between the two cohorts.

Current clinical trials indicate that the addition of pertuzumab to trastuzumab for neoadjuvant and adjuvant chemotherapy in HER2-positive breast cancer can increase the efficacy of anti-HER2 therapy. Von Minckwitz et al. showed that the 3-year DFS significantly improved in the APHINITY trial, which was an adjuvant study of HER2-positive postoperative patients randomly assigned to receive standard chemotherapy plus 1 year of either trastuzumab and placebo or trastuzumab and pertuzumab [21]. In the APHINITY trial, anthracycline-free regimen was used in $22.3 \%$ and $21.9 \%$ of the patients in the pertuzumab group and placebo group, respectively [21]. The NeoSphere trial showed a significant increase in the pCR after addition of pertuzumab to trastuzumab-docetaxel neoadjuvant treatment. Subsequently, the NeoSphere trial reported that the 5-year DFS rate of patients receiving pertuzumab, trastuzumab, and docetaxel was higher than those receiving trastuzumab and docetaxel [22]. We also reported a network meta-analysis of neoadjuvant therapy for HER2-positive breast cancer, which revealed that the addition of pertuzumab to trastuzumab and chemotherapy significantly improved pCR compared with trastuzumab
Table 5 Baseline characteristics of cT2N0 patients

\begin{tabular}{llll}
\hline & $\begin{array}{l}\text { No anthracycline } \\
(n=44) \\
\text { No. }(\%)\end{array}$ & $\begin{array}{l}\text { Anthracycline } \\
(n=39) \\
\text { No. }(\%)\end{array}$ & $P$ value \\
\hline $\begin{array}{l}\text { Median, follow-up } \\
\text { period(month) }\end{array}$ & 51.4 & 62 & 0.18 \\
$\begin{array}{l}\text { Median, age(year) } \\
\text { ER }\end{array}$ & 64.5 & 57 & $<0.001$ \\
$\begin{array}{l}\text { Positive } \\
\text { Negative }\end{array}$ & $29(66)$ & $21(54)$ & 0.37 \\
$\begin{array}{l}\text { PgR } \\
\text { Positive }\end{array}$ & $15(34)$ & $18(46)$ & \\
Negative & $25(57)$ & $19(49)$ & 0.51 \\
Neoadjuvant chemotherapy & $20(51)$ & \\
Yes & $27(61)$ & $24(62)$ & 1 \\
No & $17(39)$ & $15(38)$ & \\
Recurrence & $4(9.0)$ & $7(12.8)$ & 0.723 \\
\hline
\end{tabular}

$E R$ estrogen receptor, $P g R$ progesterone receptor

and chemotherapy (odds ratio, 2.36; 95\% CI 1.29-4.31; $P<0.01$ ) [23, 24]. The 2018 NCCN guidelines stated that dual HER2 blockade therapy with pertuzumab, trastuzumab, and chemotherapy is one of the preferred regimens in the adjuvant treatment of patients with HER2positive breast cancer [15]. The results of our study and those of aforementioned studies indicate the possibility of safe anthracycline omission when applying HER2 blockade therapy in neoadjuvant and adjuvant settings. As more patients receive pertuzumab with trastuzumab, we expect that more patients may be able to safely omit anthracycline.

In conclusion, our results suggest that anthracyclinefree chemotherapy regimen can be an appropriate option for selected patients with HER2-positive breast cancer, with cT1N0 or cT2N0 and who achieved pCR after neoadjuvant chemotherapy.
Fig. 2 Patients who received neoadjuvant chemotherapy. $p C R$ pathological complete response

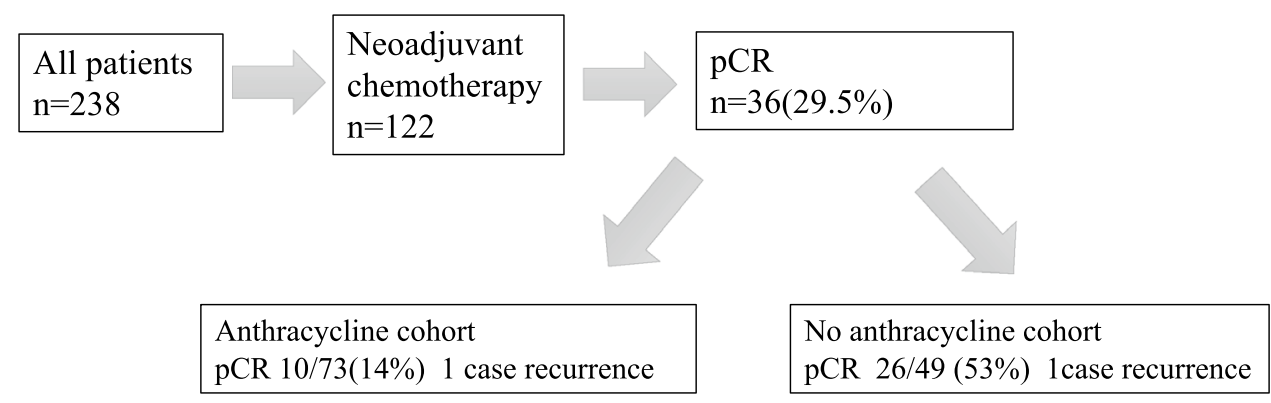


Acknowledgements This research did not receive any specific Grant from funding agencies in the public, commercial, or not-for-profit sectors.

\section{Compliance with ethical standards}

Conflict of interest T. Hayashida received research grants from Chugai, Kyowa Hakko Kirin and Shionogi and lecture fee from Chugai and Pfizer. Y. Kitagawa received research grants from Chugai, Kyowa Hakko Kirin and Shionogi, and lecture fee from Chugai. These are not directly unrelated to this study. All remaining authors have no conflicts of interest to declare.

\section{References}

1. Seshadri R, Firgaira FA, Horsfall DJ et al (1993) Clinical significance of HER-2/neu oncogene amplification in primary breast cancer. The South Australian Breast Cancer Study Group. J Clin Oncol 11(10):1936-1942

2. Slamon DJ, Clark GM, Wong SG et al (1987) Human breast cancer: correlation of relapse and survival with amplification of the HER-2/neu oncogene. Science 235(4785):177-182

3. Slamon DJ, Godolphin W, Jones LA et al (1989) Studies of the HER-2/neu proto-oncogene in human breast and ovarian cancer. Science 244(4905):707-712

4. Schramm A, De Gregorio N, Widschwendter P et al (2015) Targeted therapies in HER2-positive breast cancer-a systematic review. Breast Care (Basel) 10(3):173-178

5. Wuerstlein R, Harbeck N (2017) Neoadjuvant therapy for HER2-positive breast cancer. Rev Recent Clin Trials 12(2):81-92

6. Perez EA, Romond EH, Suman VJ et al (2014) Trastuzumab plus adjuvant chemotherapy for human epidermal growth factor receptor 2-positive breast cancer: planned joint analysis of overall survival from NSABP B-31 and NCCTG N9831. J Clin Oncol 32(33):3744-3752

7. Piccart-Gebhart MJ, Procter M, Leyland-Jones B, et al (2005) Trastuzumab after adjuvant chemotherapy in HER2-positive breast cancer. N Engl J Med 353(16):1659-1672

8. Romond EH, Perez EA, Bryant J, et al (2005) Trastuzumab plus adjuvant chemotherapy for operable HER2-positive breast cancer. N Engl J Med 353(16):1673-1684

9. Yu AF, Mukku RB, Verma S, et al (2017) Cardiac safety of nonanthracycline trastuzumab-based therapy for HER2-positive breast cancer. Breast Cancer Res Treat 166(1):241-247

10. Giordano SH, Lin YL, Kuo YF, et al (2012) Decline in the use of anthracyclines for breast cancer. J Clin Oncol 30(18):2232-2239

11. Burstein HJ, Piccart-Gebhart MJ, Perez EA et al (2012) Choosing the best trastuzumab-based adjuvant chemotherapy regimen: should we abandon anthracyclines? J Clin Oncol 30(18):2179-2182

12. Morris PG, Hudis CA (2010) Trastuzumab-related cardiotoxicity following anthracycline-based adjuvant chemotherapy: how worried should we be? J Clin Oncol 28(21):3407-3410

13. Tolaney SM, Barry WT, Dang CT et al (2015) Adjuvant paclitaxel and trastuzumab for node-negative, HER2-positive breast cancer. N Engl J Med 372(2):134-141

14. Jones SE, Collea R, Paul D, et al (2013) Adjuvant docetaxel and cyclophosphamide plus trastuzumab in patients with HER2-amplified early stage breast cancer: a single-group, open-label, phase 2 study. Lancet Oncol 14(11):1121-1128

15. National Comprehensive Cancer Network website. http://www. ncen.org

16. Curtis LH, Hammill BG, Eisenstein EL et al (2007) Using inverse probability-weighted estimators in comparative effectiveness analyses with observational databases. Med Care 45(10 Supl 2):S103-S107

17. Cole SR, Hernan MA (2004) Adjusted survival curves with inverse probability weights. Comput Methods Programs Biomed 75(1):45-49

18. Hernan MA, Robins JM (2006) Estimating causal effects from epidemiological data. J Epidemiol Community Health 60(7):578-586

19. Austin PC (2009) Balance diagnostics for comparing the distribution of baseline covariates between treatment groups in propensity-score matched samples. Stat Med 28(25):3083-3107

20. Kanda Y (2013) Investigation of the freely available easy-to-use software 'EZR' for medical statistics. Bone Marrow Transplant 48(3):452-458

21. von Minckwitz G, Procter M, de Azambuja E et al (2017) Adjuvant pertuzumab and trastuzumab in early HER2-positive breast cancer. N Engl J Med 377(2):122-131

22. Gianni L, Pienkowski T, Im YH et al (2016) 5-year analysis of neoadjuvant pertuzumab and trastuzumab in patients with locally advanced, inflammatory, or early-stage HER2-positive breast cancer (NeoSphere): a multicentre, open-label, phase 2 randomised trial. Lancet Oncol 17(6):791-800

23. Nakashoji A, Hayashida T, Yokoe T et al (2018) The updated network meta-analysis of neoadjuvant therapy for HER2-positive breast cancer. Cancer Treat Rev 62:9-17

24. Nagayama A, Hayashida T, Jinno $\mathrm{H}$ et al. Comparative effectiveness of neoadjuvant therapy for HER2-positive breast cancer: a network meta-analysis. J Natl Cancer Inst. 2014;106(9)

Publisher's Note Springer Nature remains neutral with regard to jurisdictional claims in published maps and institutional affiliations. 